\title{
Chapter 6 \\ Oil Spills from Shipping: A Case Study of the Governance of Accidental Hazards and Intentional Pollution in the Baltic Sea
}

\author{
Björn Hassler
}

\begin{abstract}
Despite most tankers being more technically safe than in the past, the increasing volume of transportation probably outweighs most, if not all, technical safety gains. Two major types of threats to the Baltic Sea environment caused by oil pollution are discussed in this chapter: accidental and intentional spills. It is shown that individual countries or coalitions have influenced governance outcomes in both areas. The introduction of double hull regulations by IMO was speeded up significantly by unilateral action taken by the USA and the EU. The move towards differentiated port controls has probably increased efficiency since it has made it possible to target substandard vessels. The Paris MoU has been important in ensuring coherent inspection practices. Intentional oil spills typically result from unlawful cleaning of tanks and engine rooms at sea. Flight surveillance and the No-Special-Fee system have been adopted to reduce oil spills. However, both mechanisms suffer from weaknesses caused by differences in countries' capacities and priorities. Flight surveillance intensity differs significantly among HELCOM member states, which makes it possible for tankers to avoid detection. The No-Special-Fee system has been only partially effective, due to varying interests and capacities of individual Baltic Sea countries, port authorities and ports.
\end{abstract}

Keywords Oil transportation • Double hulls • Oil spill • Port State Control • IMO

\subsection{Introduction}

Oil transportation has increased significantly in the Baltic Sea over the last couple of decades. There are 17 major oil ports in the Baltic Sea, and the volume of transported oil now exceeds 250 million tonnes yearly. It is expected that these amounts

\footnotetext{
B. Hassler $(\bowtie)$

School of Natural Sciences, Technology and Environmental Studies, Södertörn University, 14189 Huddinge, Sweden

e-mail: bjorn.hassler@sh.se
} 
will continue to grow. In parallel with the increased transportation of oil, vessels have on average become larger which has important implications in terms of worstcase scenarios of accidents.

The large amounts of oil being transported over the ecologically sensitive Baltic Sea create substantial environmental hazards. These risks are of two quite different and distinct types. On the one hand, there are accidental spills and on the other intentional spills caused by, for example, not taking proper care of polluted spill water. Accidents caused by collisions, fire, groundings, technical malfunctions, human error or other factors may result in large-scale oil spills. Depending on the amount of oil being carried, geographical area, type of oil, water temperature, icy conditions, wind and currents, damages to ecological systems, local tourism, recreation, real estate values and fisheries vary but could in worst-case scenarios be devastating. Fortunately, the safety of modern tankers in terms of its potential environmental costs has increased quite markedly during the last few decades due to increased emphasis placed on vessel construction and on-board installations such as advanced navigation equipment (Knudsen and Hassler 2011). In contrast, intentional spills are typically small in size, but because of their large number, the cumulated impact on the ecological integrity of the Baltic Sea is probably substantial, although detailed assessments of such spills are not available. Despite the illegality of these spills, they have been difficult to substantially curb. Due to ineffective monitoring in certain areas of the Baltic Sea and the difficulties to spot polluters and make them pay fines means that the practice of, for example, cleaning oily tanks at sea continues. However, as shown in this chapter, other ways to reduce intentional oil spills have been attempted with some success.

Contemporary marine governance in the area of shipping comprises a mix of carefully crafted hierarchical structures and horizontal interactions among a multitude of stakeholders (Bennet 2000; Knudsen and Hassler 2011; Mason 2003; Mitchell 1994). Compared with many other environmental risk areas, shipping is governed by a relatively clearly defined chain of command in terms of governance where all key global conventions have been placed under the umbrella of the UN organisations' IMO (International Maritime Organization) and ILO (International Labour Organization), after having been agreed upon by the member states. Ultimately, the implementation of adopted conventions, however, must be done at the national level, primarily in the form of Flag and Port State Control. It has been shown that although the Flag State according to UNCLOS has the formal responsibility for all ships flying its flag, Port State Control has become the most important mechanism to improve safety in global shipping (DeSombre 2006; Knapp and Frances 2008).

To understand actual governance outcomes, incentives as well as structures have to be carefully considered. Management of oil spill risks in the Baltic Sea is clearly affected not only by global conventions but often as importantly by the actions of the EU, by intergovernmental organisations such as HELCOM (Helsinki Commission) and by individual governments with strong interests and high capacity to take action on particular issues. Much of the focus in recent governance literature has been placed on interaction between institutions and stakeholders at different 
scales and the importance of including non-state stakeholders (Bach and Flinders 2004; Joas et al. 2008; Oberthür and Gehring 2006). In this chapter, it is argued that while global structures are important, contemporary multilevel and multi-actor governance patterns cannot be grasped without also including the roles played by individual countries and intergovernmental organisations. These actors are often driven by issue-specific interests but also bound by restrictions in terms of resource shortages and level of organisational skills. The focus of this chapter is on different measures that have been taken to reduce risks of accidental oil spills and strengthen operators' incentives to follow rules and norms on intentional pollution. It will be argued that the EU plays an important role both as regulator and enforcer in marine environmental governance, namely, in between the regional (HELCOM) and the global level (IMO/ILO). HELCOM, on the other hand, plays an important mediating role between national interests among the Baltic Sea countries and regulations in the EU and IMO. Furthermore, it will be argued that individual countries play important roles in specific governance situations, especially when they perceive strong national interests to be at stake. Mechanisms to facilitate proactive governments taking action when it is in their interest to do so could in certain situations contribute to improved and more sustainable governance.

The remaining part of this chapter is structured as follows. After a brief section on ecological and economic impacts of oil spills, we have a section on measures to reduce accidental spills and mitigate intentional spills. Examples of both command and control as well as incentive-based measures are given. The chapter concludes with a discussion on possible ways ahead, with a particular focus on what roles the EU and HELCOM can play in regional governance of marine oil transportations.

\subsection{Ecological and Economic Consequences of Marine Oil Spills}

The direct effects of large-scale oil spills are easy to observe. Seabirds and mammals especially may suffer and die in large quantities. Beaches may become unusable for recreation activities, and local fisheries can be devastated for a number of years. Laboratory studies have shown that oil can have deadly as well as sublethal effects upon organisms. Field studies after accidents have shown significant negative effects on affected ecosystems (National Research Council 2003). However, it is almost impossible to predict the long-term consequences from a significant oil spill, because of at least three different types of uncertainty.

First, the location of the spill is crucial (French-McCay 2009). Typically, the farther away from shores the spill occurs, the more time is available for limiting the geographical distribution of the spill, to fence off sensitive areas and set up cooperative cleanup schemes among authorities from different countries. This normally results in a more limited impact. Moreover, depending on the local ecological sensitivity and economic importance of the affected area, consequences may vary considerably. 
Second, depending on the type of oil being spilled, weather conditions and sea currents, the ecological and social impacts can vary dramatically. For example, icy conditions make cleanup activities especially cumbersome. Third, the long-term effects of oil spills on complex ecosystems are not well known (National Research Council 2003). Whether or not oil sinks to the bottom and continues to affect specific communities and ecosystems for a long time depends on the type of oil and local conditions. Possibly, oil spills can increase physiological stress, reduce food supply and cause reproduction disturbances.

Taken together, these uncertainties make it impossible to in detail predict impacts of large-scale oil spills. Although political agreements may be reached on the importance of reducing risks, questions related to which particular measures are most cost-efficient cannot be definitely given as long as it is not possible to assess risks in detail.

The ecological impact of the many almost continuous small-scale intentional spills that take place in the Baltic Sea is quite different from the large-scale ones and more difficult to delineate. Although it could be expected that operators choose to clean tanks in ways that minimise risks of being spotted, existing data on where oil spills have been detected show a rather uniform distribution during the last 10 years along the major sea lanes (possibly with some clusters at the entrance of the Gulf of Finland and in the Great Belts) (HELCOM 2014). There are four kinds of major environmental concerns linked to intentional spills. First, many small spills occur close to ports as a result of loading and unloading and may cause disturbances to local ecosystems. Most of these spills are not intentional, but rather the result of improper procedures or human error. Despite this, they are typically classified as "intentional" in order to distinguish them from large-scale accidental spills. ${ }^{1}$ Second, even though these smaller spills occur along the major shipping lanes in general, there seem to be some clusters where spills are more common. Environmental hazards typically increase the denser these clusters are. Third, where the spills take place is of importance. Comparably large spills in favourable weather conditions and far away from ecologically sensitive areas may not cause much observable harm, whereas small spills could cause substantial damage if they occur close to sensitive areas, in unfavourable weather conditions and in critical seasons when different marine-living species might be reproducing. Finally, the Baltic Sea is an ecologically sensitive sea because of its brackish water, slow water exchange with the North Sea and the halocline (salinity gradient) that reduces vertical mixing of water and thereby leads to reduced oxygen concentrations in deep basins.

\footnotetext{
${ }^{1}$ It could be argued, for example, that operational spills might be a better label than intentional spills, as the former places the focus on oil spills that result from everyday procedures rather than from accidents. However, since intentional spills is the term used in most of the literature, we have chosen to stick to this term when referring to small-scale spills caused by negligence, improper procedures or something similar.
} 


\subsection{Marine Environmental Safety Drivers}

Probably the most important measure to reduce risks of large-scale accidental oil spills has been the requirement of double hulls. The double hulls of modern vessels means that the risk of oil spills are significantly reduced in case of a grounding or collision. In a 1992 amendment of MARPOL, it was stipulated that no large tankers (5,000 Deadweight tonnage or more) without double hulls could be ordered after 1993 unless IMO had recognised alternative designs that were deemed to be acceptable from an environmental safety perspective. However, since the conversion of single-hull tankers is complicated and the expected lifetime of vessels constructed before 1993 is up to 30 years, a complicated and prolonged phase-out process was elaborated by IMO. As will be described below, this phase-out process was subsequently speeded up, partly due to some large-scale accidents and partly due to unilateral action on prohibition of single-hull vessels by the USA and later by the EU.

A quite different type of environmental hazard is caused by operators' cutting corners. In order to save time and money, operators often get tanks illegally cleaned and flush machine rooms at sea, rather than in port where oily wastes could be taken care of properly. In some cases, these types of spills might not be intentional in a strict sense but nevertheless are caused by negligence or improper procedures. The number of observed illegal spills has been decreasing over the last two decades, although the number of unrecorded cases is probably substantial. While the number of flight surveillance hours to combat illegal pollution increased during the $1990 \mathrm{~s}$ and then levelled off during the 2000s, the number of detected spills declined over the last 10 years from approximately 500 in the late 1980 s to around 130 in the last couple of years (HELCOM 2014). The introduction of satellite monitoring by EMSA (European Maritime Safety Agency) over the last 5 years has been instrumental in directing aerial and marine surveillance. The long-term ecological effects of this diffuse form of pollution of the Baltic Sea are not known in detail but could potentially be substantial.

To understand why some measures to reduce oil spills in the Baltic Sea have been more successful than others, why some measures are better handled at regional levels and others through global conventions and why some countries seem to be more proactive than others, it is important to consider differences in interests and capabilities (Hassler 2010). First, environmental hazards that are global in nature typically require global conventions, as regulations at regional and subregional levels tend to invite free riding and market distortions where actors act strategically to avoid costs and reap benefits without contributing to the realisation of collective goods (Keohane 2002). For example, as we discuss further below, tanker construction needs to be regulated globally. Although it could be suggested that the Flag State responsibility ought to be enacted more forcefully as a way to counteract collective action dilemmas, the emergence of open registries has made this very difficult, if not impossible. On the other hand, measures taken by individual countries to improve environmental safety that primarily give local effects may escape the "Tragedy of the commons" (Hardin 1968). It has been shown that measures such as 
improved hydrographical measurements and navigation charts, not only in domestic waters but also in collaboration with neighbouring countries, have been successfully undertaken (Hassler 2011). The global features of marine oil transportation are not what is important, but rather the fact that the country carrying the costs is also the prime beneficiary of the undertaken project. Whether to make this investment or not thus becomes an issue of domestic cost-benefit analysis which does not need to turn into a tragedy of the commons. Basically, it then becomes a question for the authorities in that country to decide how to finance this investment.

Second, different countries will benefit disproportionally from most kinds of pollution control. Countries with extended coastlines close to major marine traffic lanes, for example, are typically more vulnerable to oil spills. It could be expected that these countries would be more proactive vis-à-vis stricter regulations, everything else being equal. Not only would these countries be expected to undertake measures having primarily local effects as described above, but proactive positions in relation to international regulation would also be anticipated. Considering that lobbying for stricter international regulation is typically not costly in relation to what could be gained in case of successful interventions, there is no reason to expect barriers for collective action in these cases, given that domestic interests are sufficiently strong. This is most likely one important reason why Sweden and Finland have been strong proponents of stricter international regulations with regard to environmental hazards in the Baltic Sea, not only when it comes to marine oil transportation but to most other threats to the integrity of Baltic Sea ecosystems as well. In a similar manner, but conversely, countries with large stakes in marine oil transportation could be more hesitant to accept costly measures to reduce risks of oil spills. This would, according to the logic of collective action rationality, especially apply to stricter international regulations since these might threaten economic interests. On the other hand, local improvement in, for example, port facilities or hydrographical charts could be more appealing for countries in geographically vulnerable situations.

Third, and finally, not only interests matter, but capability as well. Countries with more resources, know-how and experience could be expected to be more proactive in relation to risk prevention as well as the build-up of impact reduction and cleaning up capability compared with countries that have less resources and experience with these issues. This aspect has considerable relevance in the Baltic Sea region as there is a marked difference in resource availability and administrative experience between the former Soviet Union states on the one hand and the Nordic states and Germany on the other. This has had significant implications not only for national environmental management, transposition of EU regulations and implementation of international agreements but also in a wider, regional sense. It has been shown, especially during the first decade of independence in the 1990s, that the Nordic states influenced the Baltic States by giving targeted support to strengthen their administrative capability and assisting them in their preparation for becoming EU members (Hassler 2003a).

It is clear in summary that perceiving environmental governance of marine transportation as globalised and therefore uniformly prone to collective action problems 
is overly simplistic. To understand what would be the main drivers in effective marine governance, it is necessary to disentangle individual actors' - governments', sector organisations', operators', NGOs' and others' - interests in specific cases and analyse how these interests contribute to collective outcomes. In some cases, notably where costs and benefits from an undertaking fall upon a single actor, problems related to collective action should not be expected. ${ }^{2}$

\subsection{Undertaken Measures to Reduce Oil Spills in the Baltic Sea}

Turning now to the type of measures that have been taken to reduce risks related to marine oil transportation, it is clear that large-scale accidental oil spills and intentional limited spills are similar in the sense that management suffers from significant amounts of uncertainty. However, different types of uncertainty in these areas mean that different types of measures need to be taken to reduce oil pollution in the Baltic Sea. For example, regarding accidental spills vessel construction is of crucial importance. Since most vessels are sailing in waters in different parts of the world, uniform rules are typically required to induce compliance. When it comes to intentional spills, on the other hand, most spills are operational in nature, implying that monitoring and surveillance is required. In addition to the distinction between accidental and intentional spills, it is helpful to distinguish between command and control measures (binding regulations) and various incentive schemes aimed at altering actors' behaviour in more environmentally friendly directions (to reduce accidental risks and intentional spills). The latter are predominantly based on economic incentives (e.g. differentiated tariffs) but could also comprise other forms of incentives, such as benchmarking and environmental labelling. The distinction between command and control mechanisms and incentive schemes is important since it directly ties to the above discussion on actors' varying interests. Aspects that need uniform, global regulation typically call for global command and control mechanisms, mainly because of the difficulties of administrating a global incentive scheme, such as a uniform environmental tax on fuels. The main problem with command and control regulation is low levels of implementation and compliance. ${ }^{3}$ Whereas the key rationale of command and control measures is uniform application, the opposite could be said to hold for incentive-based schemes. Although the

\footnotetext{
${ }^{2}$ It could be argued that problems related to collective action may re-emerge at the national level, since various actors at the domestic level can be assumed primarily to promote particular rather than joint interests. However, since the hierarchical structure is much stronger at the national level compared to the international, collective action aspects are in most cases not as serious at the national level.

${ }^{3}$ That some members refrain from being members of IMO, which is the most important global authority on marine affairs, is not a major problem as the number of members now has reached 170 (IMO 2011a). While not all member countries have signed and ratified all individual conventions, the even bigger problem is the lack of implementation and compliance of ratified conventions.
} 
Table 6.1 Matrix showing four examples of different categories of marine oil spill control

\begin{tabular}{l|l|l}
\hline & Command and control & Incentive schemes \\
\hline Accidental spills & Double hulls & Differentiated Port State control \\
\hline Intentional spills & Flight surveillance & Integrated port reception fees
\end{tabular}

framework as such should be applied uniformly, the bearing idea is to differentiate among actors depending on individual behaviour. Preferred behaviour should be awarded, while unwanted choices should be penalised. To make such a scheme effective, it is imperative to know the main drivers of key actors.

In Table 6.1 the distinctions are shown between, on the one hand, accidental and intentional spills and, on the other hand, command and control mechanisms and incentive schemes. In the rest of this section, examples of each of these four combinations are discussed. It should be noted that (a) the cases given are far from exhaustive but should be viewed as illuminating examples and (b) some examples may exhibit both command and control and incentive-based mechanisms, something that will be discussed below.

\subsection{Accidental Spills}

\subsubsection{Command and Control Measures: EU (and US) Influence over the Phasing out of Single-Hull Tankers}

In the early 1600s, Hugo Grotius formulated the idea of a Mare Liberum, the freedom of the seas, a principle stating that all states have the right to use the sea for transportation and trade. This idea was later codified in UNCLOS (United Nations Convention of the Law of the Seas). The bearing idea in UNCLOS is that innocent passage should always be allowed (Article 17) and that it is the responsibility of the Flag State to make sure that vessels carrying its flag follow all valid international agreements (Article 94). It is moreover the Flag State that is responsible for carrying out investigations when incidents occur.

IMO (the International Maritime Authority) is the main intergovernmental authority governing the seas. IMO was established in 1948, but it was not until 1958 that the first convention entered into force and the work could begin. During the first decades of its operation, IMO's focus on environmental protection stressed the need for regulating and monitoring of intentional spills and operating procedures (Mitchell et al. 1999). Rules were devised with regard to maximum oil contents in spill water and how far from the coast such pollution was allowed (Hassler 2010). However, it soon became apparent that it was not possible to effectively control operational procedures at sea, mainly because of the vast geographical areas that had to be covered but also because of the inadequacy of Flag State control (Knudsen and Hassler 2011). When it became clear that monitoring and Flag State enforcement were not effective, more focus was put on easily controllable requirements. 
The most obvious of such requirements were directly related to vessel construction and retrofitting. When new vessels are ordered, the purchaser needs to make sure that it complies with the most recent IMO conventions; otherwise the Classification Society will not grant the needed permit. In other words, there is a rather effective and efficient mechanism for making sure that new vessels comply with existing regulations. Interestingly, private actors - Classification Societies - play a crucial role in making these command-and-control measures effective.

The institutionalised system of Port State Control is undertaken on selected vessels so as to ensure that required safety installations are operational. The major weakness of this system is that there are no guarantees that installed safety equipment actually are used in accordance with proper procedures. A major determining factor of whether such equipment is used or not is the extent the operator has economic or other incentives not to use installed equipment. When proper use is not costly, or even beneficial to the operators, it could be expected that intended procedures are adhered to. On the other hand, when operators gain from cutting corners by not using installed equipment, technical requirements are typically not sufficient.

The ongoing international phasing out of single-hull tankers is probably the single most important initiative that has been taken to increase environmental safety in relation to accidental large-scale oil spills. In what follows, the importance of phasing out single-hull tankers will be elaborated upon. Attention is also given to how individual countries may take unilateral action in order to protect what is perceived to be of national interest and how large-scale accidents can create momentum for adoption of stricter regulation.

The first initiative to phase out single-hull tankers was taken unilaterally in 1990 by the USA (Oil Pollution Act; OPA 90) as a direct consequence of the 1989 Exxon Valdez accident. The US ban meant that neither new nor old tankers with single hulls would be allowed to call on US ports after 2005. IMO reacted to the US ban in 1992 when it accepted an amendment of MARPOL that stated that large tankers (over 5,000 Deadweight tonnes) must have double hulls if ordered after July 1993 (MARPOL, Annex I, Regulation 19). However, the issue of how to phase out singlehull tankers which were in use without creating too much disruption in marine transportation was more difficult to agree upon. Initially, it was decided in IMO that existing tankers should either be converted or taken out of service before they were 30 years old (MARPOL, Annex I, Regulation 20). ${ }^{4}$ EU authorities, faced by a situation where all single-hull tankers would be denied access to US ports in 2005 following the serious Erika (1999) and Prestige (2002) oil spills, realised that there was a high probability that the unilateral decision by the USA would result in a redirection of single-hull ships from the USA to other parts of the world (Summaries of EU

\footnotetext{
${ }^{4}$ The 30 year limit was, however, not absolute but could be adapted to, e.g. bottlenecks in shipyards' capability to handle conversions to double hulls and to whether the vessel had segregated ballast tanks or not. Owners could therefore ask IMO for extension periods for their vessels on individual basis. However, because of the difficulties in retrofitting existing vessels, it was assumed that older tankers would rather be taken out of service than converted.
} 
Legislation 29-08-2011; Aksu et al. 2004). EU ports could thus be expected to receive a larger share of single-hull tankers than before (Regulation (EC) No 417/2002). As a reaction to this threat, the EU enacted a unilateral speeding up of the phasing-out timetable that had already been established in the US OPA 90, stipulating that no Category 1 tankers would be allowed to enter any port in any EU country or carry the flag of any EU member country after 2005 (Regulation (EC) No 417/2002). Vessels constructed in 1980 or earlier would not be allowed after 2003 and those constructed in 1981 not after 2004. Category 2 and 3 tankers were given a deadline of 2010, with the newest vessels being given deadlines furthest into the future. However, vessels in Category 2 and Category 3 that were older than 15 years in 2005 were subjected to enhanced surveys - so-called Condition Assessment Scheme (CAS) - especially targeting structural weaknesses in single-hull vessels (Regulation (EC) No 417/2002). Faced by considerable pressure from the EU (Höfer 2003), IMO attempted a speed-up of the single-hull phase-out and a revised schedule entered into force in 2003 (MARPOL Regulation 13 G). In December 2003 additional revisions were made, stipulating that Category 1 tankers (large vessels not having segregated ballast tanks) had to be phased out no later than 2005 . Category 2 tankers (large tankers with segregated ballast tanks) and Category 3 tankers (small vessels) were required to have double hulls from 2010 onwards, not 2015 as previously decided (IMO 2012-06-29). The Flag State could, however, still give permission for Category 2 and 3 tankers according to what was stipulated in the IMO CAS (Condition Assessment Scheme), to continue operation until 2015 or until they were 25 years old. This brief review of the phasing out of single-hull vessels is an interesting example of how dominant players (the USA and EU) interact with an intergovernmental authority (IMO) on command and control measures related to environmental safety. ${ }^{5}$ The USA and EU pushed forward the phasing out of single-hull oil tankers, thus facilitating a global phasing out through IMO mechanisms. They were able to do this due to their large share of the world market. They had to do this because of domestic political pressures to increase safety in marine oil transportation and perceived dangers in being negatively affected by unilateral action by others. ${ }^{6}$

\footnotetext{
${ }^{5}$ However, it should be noted that although UNCLOS regulations on the right of Port State Control have been important in the regime for in-phasing of double hull vessels, double hulls are probably not a panacea for improved safety. It has been shown that these constructions often are harder to inspect and that inadequate technical solutions and poor maintenance may result in only limited safety enhancements.

${ }^{6}$ Although relevant IMO regulations do not have complete global coverage, MARPOL Annex I/II has been ratified by 150 countries (2011b), representing more than $99 \%$ of global merchant shipping tonnage (IMO 2011a).
} 


\subsubsection{Incentive Schemes: The Case of Selective Port Inspections in the Baltic Sea and Other European Waters}

Environmental governance schemes based on incentive mechanisms rather than on command and control regulations typically use taxes or subsidies to alter behaviour in preferred directions. These schemes have become widely used especially at the national level mainly because they increase economic efficiency when designed appropriately, that is, when externalities are internalised into companies' and organisations' budgets. Theoretically, although often difficult to achieve in real situations where lack of information, uncertainty and strategic behaviour interfere with management objectives, taxes could be tuned to perfectly offset externalities such as negative environmental effects from industrial production or transportations. This would make it rational for targeted actors to reduce pollution until the marginal cost of environmental side effects equals marginal pollution reduction costs.

Unfortunately, preconditions for successfully establishing economic incentive schemes at the international level are radically different. It has proven difficult to find robust systems to tax use of ecosystem services and natural resources in the international commons as they are not under any single country's jurisdiction. The highly globalised marine transportation sector is no exception and is indicative of the fact that almost no environmental taxes have been successfully and uniformly applied in this area. However, there are other than economic ways to influence actors' behaviour through altered incentives. Similar to taxes and subsidies, these other incentive-based mechanisms ideally should be constructed so that behavioural change among targeted actors result in as large positive environmental effects as possible in relation to costs inferred. In other words, actors that behave well should come out better than those behaving not so well.

The modern Port State Control is an interesting example of such an incentivebased mechanism where regional Memoranda of Understandings (MoUs) have been instrumental in coordinating port inspections. In this brief example, the focus is placed on the Paris MoU, an organisation established in 1982 and comprising today 26 European member countries plus Canada and the EEC. ${ }^{7}$ Until quite recently, about $25 \%$ of visiting ships were randomly selected for inspection, but in January 1, 2011, the so-called NIR (New Inspection Regime) was implemented (Paris MoU 2012c). In the NIR regime, all vessels are assessed when calling at Paris MoU ports and those that are believed to be more likely to have safety deficiencies selected for inspection. In order to build up a legitimate basis for the selection of risky vessels, a centralised database has been established under the auspices of EMSA (European Maritime Safety Authority). The ship risk profile is updated daily, and specific vessels are selected based on parameters such

\footnotetext{
${ }^{7}$ Apart from the Paris MoU, there are nine other regional sister authorities throughout the world: Abuja MoU, Black Sea MoU, Caribbean MoU, Indian Ocean MoU, Mediterranean MoU, Riyadh MoU, Tokyo MoU, Asia Pacific Region and Viña del Mar Agreement Latin American Region.
} 
as previous history of detected deficiencies, age and company performance. ${ }^{8}$ All vessels that have been classified as high-risk ships have to make a port call at least $72 \mathrm{~h}$ before planned arrival in order to facilitate expanded inspections by the port authorities. Failure to report notifications as is required for all visiting ships may result in selection for inspection, irrespective of prior ship profile. It may also result in fines depending on national regulations in the Port State. The ports where these ships are heading will then carry out an inspection according to criteria stipulated in IMO regulations (Paris MoU 2012a). If the inspectors find major deficiencies, the vessel may be detained until these have been corrected. Repeated detentions may in turn result in banning from all Paris MoU member countries' ports for a specified period of time.

Inspections take time and therefore create direct costs for companies. Being classified as a high-risk ship may moreover result in indirect costs for the companies as this may impact upon insurance costs as well as the willingness of cargo owners to do business with these vessel owners. The switch from the earlier procedure of random controls to targeted controls of vessels has thus resulted in strengthened incentives for operators to achieve a low-risk profile. The only way vessel owners can achieve this is to improve their record by reducing the probability of being found to have deficiencies. According to preliminary data from Paris MoU, more detentions took place, despite fewer inspections, in 2011 as compared to previous years, which seems to indicate a higher degree of inspection effectiveness (Paris MoU 2012b).

The Paris MoU has in different ways given the port inspection mechanism increased potency. This has to a significant extent been possible due to the capacities of Member States and their ability to collaborate. This form of regional cooperation is of crucial importance in international governance since formal enforcement mechanisms are lacking. One way to give these incentive-based mechanisms more clout is to make sure that the information on ship deficiencies and detentions not only are made public but are also made as easily accessible and widespread as possible. Paris MoU is primarily doing this through its homepage (http://www.parismou.org), where statistics as well as individual vessel records, risk profiles and other data are published. Finally, statistics on Flag State and Classification Society performance are published as well. Depending on the number of inspections and detentions, Flag States and Classification Societies are classified in white/grey/ black lists easily accessible to all stakeholders.

\footnotetext{
${ }^{8}$ The company performance indicator measures the frequency of found deficiencies among a company's complete fleet of vessels and may result in rankings from very low to high performance.
} 


\subsection{Intentional Spills}

\subsubsection{Command and Control: Aerial Surveillance and Monitoring of Baltic Sea Waters}

Whereas IMO has moved from vessel monitoring at sea towards focusing on vessel construction and maintenance, the situation is slightly different with regard to regional management of intentional oil spills in the Baltic Sea. All relevant IMO regulations are also valid in the Baltic Sea region, and many of them moreover have been incorporated into the Helsinki Convention. Due to the smallish size of the Baltic Sea, serious attempts have been made to monitor ship movements in order to detect oil spills. There are mainly three reasons why this form of monitoring could be important at regional and subregional levels but less effective in the large open seas of the world. First, the number of countries that need to cooperate on monitoring schemes is limited which facilitates joint action. In the case of the Baltic Sea region, the longstanding record of HELCOM being a key regional intergovernmental organisation facilitates reaching of agreements (Hassler 2003b). Second, the fact that most of the major Baltic Sea shipping lanes are within individual countries' exclusive economic zones (EEZs) and territorial waters means that these countries may find themselves to be in vulnerable positions in case of oil spills. This creates incentives for individual countries to deter operators from polluting nearby but still in international waters (Hassler 2008). Third, and finally, the limited size of the Baltic Sea makes aerial surveillance in collaboration with coastguard patrols effective enough to be worthwhile. Since April 2007, monitoring has been given more muscle through the EMSA CleanSeaNet satellite surveillance. However, even though satellite surveillance may seem like a powerful tool, HELCOM data from 2012 shows that from the 185 satellite detections of suspected spills, only 13 were later confirmed as mineral oil spills, while more than half (93) were never checked at all (HELCOM 2012).

The main responsibility of aerial surveillance rests with individual countries. Agreements have thus been reached within HELCOM that air surveillance should be undertaken by all member countries and that statistics of the number of flight hours, detected oil spills, confirmed oil spills and similar kinds of data should be reported to HELCOM. HELCOM thereafter compiles reports and makes these available to member countries as well as to the general public. In addition to this, intensified, joint surveillance efforts are undertaken once or twice a year under the programme Coordinated Extended Pollution Control Operation (CEPCO). During CEPCO operations, a 24-h surveillance scheme is carried out. On some occasions so-called Super-CEPCO operations have also been undertaken that last for 6-10 days in an attempt to improve data on pollution and reduce the number of spills. The details of these operations remain classified until after the surveillance has been carried out in order to avoid strategic actions by operators.

It is clear that ambition levels among different HELCOM member countries have varied considerably despite the fact that HELCOM Recommendation 12/8 adopted 
as far back as 1991 spoke about joint responsibility to collaborate and contribute to effective aerial surveillance. As can be seen in Fig. 6.1, the number of yearly flight hours varies considerably among HELCOM member countries, although there has been a slight upward trend over time at the aggregate level. For example, Sweden in almost all years has had more flight hours recorded than all the other countries together. Russia, in contrast, has only recorded ten flight hours between 1993 and 2011. Even though it is reasonable to expect countries with long coastlines and major sea routes to have more flight hours than others, the overall impression is that compliance with flight hour commitments is uneven.

Despite the uneven implementation of the flight surveillance schemes, available data seem to indicate that the number of intentional spills has declined over the last decade, in spite of the significant increases in marine traffic at the Baltic Sea (Fig. 6.2).

Although the interpretation of HELCOM data may seem straightforward improved command and control measures through satellite and aerial and surface monitoring have led to decreased levels of intentional oil spills - uncertainties remain regarding the number of spills as well as what drivers have been most important in the alleged reduction of intentional spills. It may very well be the case that increased surveillance has led to fewer intentional oil spills in the last decade. Most likely this is the main explanation for the declining trend shown in Fig. 6.2. However, the number of observed spills is most likely considerably lower than actual spills. It is reasonable to assume that vessel operators choose a particular time (during

\section{Number of yearly flight hours (1989-2013)}

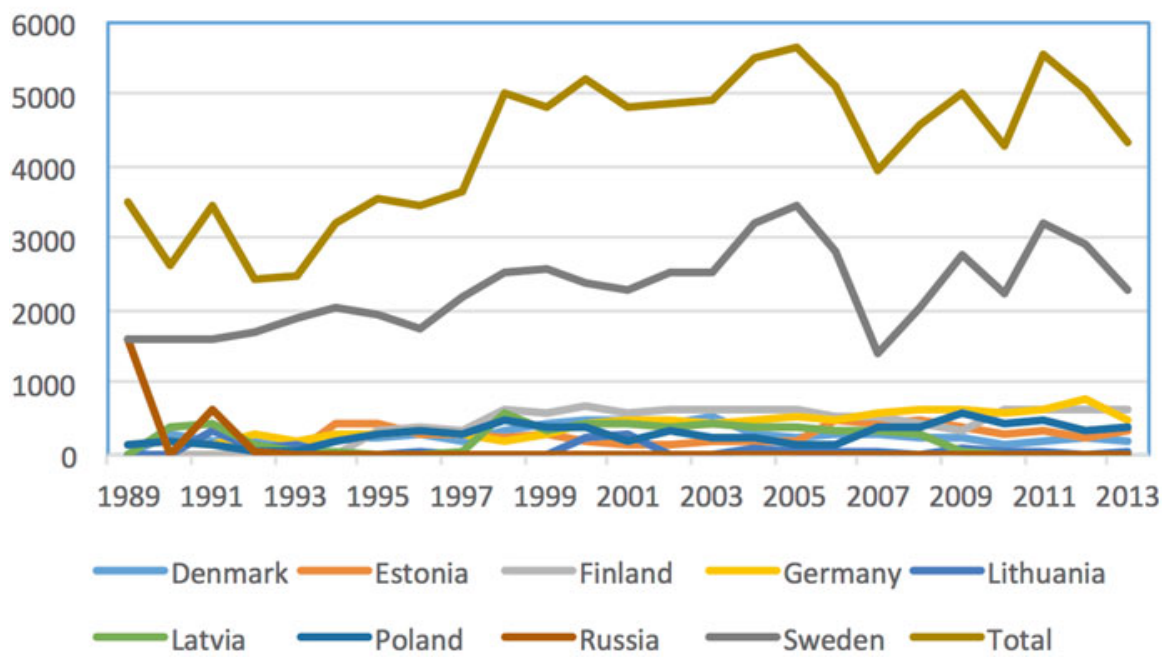

Fig. 6.1 Number of yearly surveillance flight hours between 1989 and 2013 (Adapted from HELCOM 2014) (Scores of zero flight hours in this figure represent no reported flight hours for that year or that zero flight hours have been reported) 


\section{Number of confirmed spills (1988-2013)}

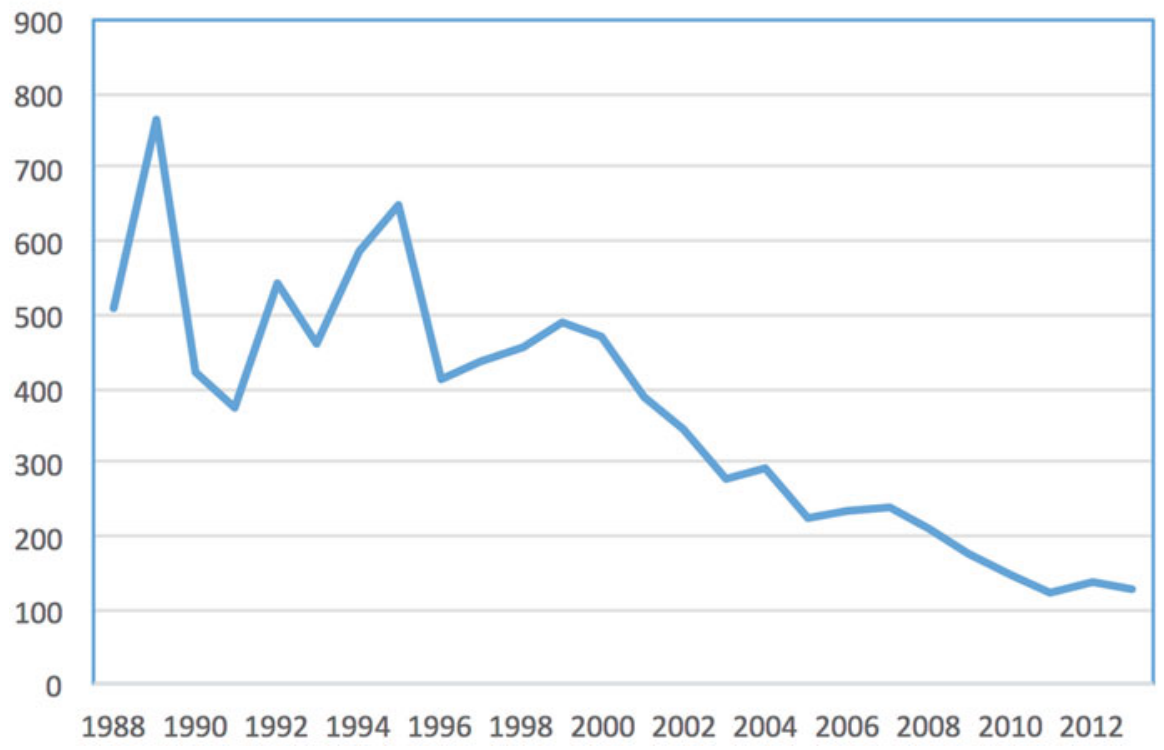

Fig. 6.2 Number of recorded intentional oil spills between 1988 and 2013 (Adapted from HELCOM 2014)

darkness) and place (areas where surveillance is known to be lax) to make intentional spills. If this is correct, the number of undetected oil spills could be substantial. Possible partial solutions to this problem could be more effective satellite surveillance, increasing the number of flight hours in darkness and using and intensifying the use of joint surveillance efforts that are not announced beforehand (CEPCO operations). Moreover, if we are in fact witnessing a reduction in the number of spills, it is likely that these command and control measures are not the only reasons for this reduction. At least two additional factors are probably important. First, as tanker fleets in the Baltic Sea are modernised, the pollution from, for example, flushing of machine rooms could be expected to decrease as spill water can be better taken care of in modern tankers. Moreover, when vessels are modernised and better adapted to existing reception facilities in the ports, the incentives to clean tanks at sea are weakened, as less time than before is needed for cleaning tanks in port. Second, the introduction of more effective reception facilities and the No-Special-Fee system (elaborated on below) means that no additional charges are made for cleaning tanks in port. Incentives for cleaning them at sea are thus reduced.

Two concerns remain regarding the effectiveness of aerial surveillance. First, member countries are responsible for covering their respective air space. This means that the engagement shown most likely will continue to vary in accordance with national capacity and priorities. Second, detection of oil spills typically do not lead to identification of the perpetrator. Only in $12 \%$ of the detected spills has the 
polluting ship been identified (HELCOM 2014). Moreover, even when the polluter is identified, it is far from certain that this leads to a conviction, and if it does, penalties are typically low. Despite the use of HELCOM AIS - a land-based tracking system that makes it possible to track all large ships in real time - and the Seatrack Web oil drift forecasting system (STW) that facilitates assessment of propagation patterns of oil spills, identification effectiveness of polluters remains poor. This obviously weakens incentives for operators to cut corners by, for example, cleaning tanks at sea.

\subsubsection{Incentive Schemes: The Baltic Sea No-Special-Fee System}

One way to reduce temptations for operators to intentionally pollute by, for example, cleaning tanks at sea is to reduce costs for abiding by MARPOL conventions that require depositing oily wastes in dedicated port reception facilities. Despite the fact that port reception facilities have been on the agenda of all MEPC meeting for the last 35 years since the advent of MEPC 3 (Mikelis 2010), facilities and operational procedures are still far from adequate in the ports of many MARPOL member countries. ${ }^{9}$

From the perspective of IMO, "MARPOL provisions require the government of each party to ensure the provision of adequate port reception facilities without causing undue delay" (IMO 1999). Moreover, according to MEPC, "The ability of ships to comply with the discharge requirements of MARPOL depends largely upon the availability of adequate port reception facilities..." (MEPC 2007). However, what constitutes "adequate port reception facilities" is almost impossible to define since the kind of facilities necessary depends on what types of vessels regularly call in ports. In smaller ports simple barrels might be sufficient, whereas in many of the larger ports, facilities have to be constructed that cannot only harbour large amounts of wastes but also treat different oil residues in different ways. The issue of how to delimit "... without causing undue delay" is not a question that is easy to solve. It is clear that every extra hour a large tanker has to stay in port costs the operator a significant amount of money. Therefore, temptations to clean tanks at sea will prevail as long as it is quicker and easier than doing so in a port, and the risk of being caught while polluting is negligible.

In order to put pressure on Port States and stimulate investments in port reception facilities, IMO has underlined the responsibility of Flag States to ensure that the IMO report format is distributed to all vessels carrying their flag. This format should be used by the master of the vessel to notify the Flag State as well as IMO and the relevant Port State when reception facilities are not appropriate or when there have been undue delays. Port States are then expected to "... ensure the provision of

\footnotetext{
${ }^{9} \mathrm{MEPC}$ - the IMO Marine Environment Protection Committee.
} 
proper arrangements to consider and respond appropriately and effectively to reports of inadequacies, informing IMO and the reporting flag State of the outcome of their investigation" (MEPC 2007).

EU's strategy in this area has been similar to the one on Port State Control referred to above. EU Directive 2000/59/EC reiterates the regulation pertaining to Port State facilities stipulated in MARPOL. ${ }^{10}$ However, this directive is different from the MARPOL Convention in two ways. First, it is only applicable to EU member countries. However, despite being applicable to EU Member States only, this does not mean that vessels from other countries are exempted. On the contrary, all vessels (except for war ships and non-commercial ships owned or operated by a State) have to abide by the procedures and regulations on handling of waste that are stipulated in the directive when entering a port of an EU country (Article 3). Second, by turning the MARPOL regulation into an EU directive, enforcement mechanisms are substantially strengthened. Port States that do not follow the directive could be taken to court.

It is stipulated in Directive 2000/59/EC that each port in every Member State has to establish a waste reception and handling plan (Article 5). This plan in turn has to be approved by the government of the Member State, and every third year at least, it has to be reapproved by the government. The Member State is moreover responsible for monitoring the implementation of the Waste reception and handling plan. In order for port authorities to prepare for inspections or other procedures, operators are required to notify the port they are calling on, where and when residues were left in their previous port visit and how much waste is still on-board. The operators are moreover required to leave residues in the port before leaving, unless they can show that they can adequately store the waste on-board. Failing to do so could mean that the ship is not allowed to leave the port (Article 7). Finally, the port is required to ensure that it covers the costs of its reception facilities. In order to do this, all visiting vessels are required to pay a certain part of the reception costs, irrespective of whether they use the port's facility or not. ${ }^{11}$ The Commission has quantified this amount to be at least $30 \%$ of total reception costs (Directive 2000/59/EC). Apart from this, fees are set in accordance with the amount of waste delivered. However, "...fees may be reduced if the ship's environmental management, design, equipment and operation are such that the Master of the ship can demonstrate that it produces reduced quantities of ship-generated waste" (Article 8c).

Against this background of initiatives taken to improve port reception facilities at the global and EU level in order to reduce the temptation to pollute at sea, the regional HELCOM No-Special-Fee system is interesting (HELCOM

\footnotetext{
${ }^{10}$ Directive 2000/59/EC entered into force on December 28, 2000. The deadline for countries to implement the directive was December 28, 2002.

${ }^{11}$ Interestingly, this may be somewhat at odds with one of the most important principles in modern environmental protection - the Polluter Pays Principle (PPP) - since operators that do not need to use port reception facilities (because of, e.g. installed on-board equipment to manage operation spill) still have to pay for this service.
} 
Recommendation 19/8). ${ }^{12}$ The HELCOM No-Special-Fee system builds on MARPOL requirements on waste reception facilities in ports and the EU demand on cost coverage. However, it focuses more on actual incentives facing operators. This system is defined as:

.... charging system where the cost of reception, handling and disposal of ship-generated wastes, originating from the normal operation of the ship... is included in the harbour fee or otherwise charged to the ship irrespective of whether wastes are delivered or not" (HELCOM Recommendation 28E/10, paragraph 1.1).

In other words, this system implies that all ships have to pay for reception, handling and disposal of residues, even if they have no residues to account for. The bearing idea behind the No-Special-Fee system is that the port fee should not be related to the amount of residues the vessel leaves in port. This would mean that - at least in theory and not taking the extra time in port needed for proper waste management into consideration - the operator would not gain from, for example, cleaning tanks at sea, since the handling of the residues is free (i.e. included in the port fee). This does not necessarily mean that all ships have to pay the same fee. A more reasonable approach is that ships pay according to a selected parameter that could be expected to vary with the average amount of waste, but not with the amount of waste deposited by a specific ship. However, it is not stipulated precisely in HELCOM Recommendation 28E/10 what particular parameter should be used. Gross tonnage as available from the ship's Data Sheet would be an easy measure, but type of cargo, number of staff and the quality of on-board installations for waste management as stated in the Recommendation could also be used. Independent of what measures are used, the principles of fee calculation should be "fair, transparent and nondiscriminatory to all ships" and ensure a high degree of legitimacy. Moreover, the collected fees should exclusively be used for costs related to waste reception in the port (HELCOM Recommendation 28E/10, paragraph 4). Finally, in order to avoid market distortions, it has been stated that "The Contracting States involved shall make the necessary efforts in order to implement a harmonised fee system simultaneously in the ports of the Baltic Sea as well as in the North Sea Regions" (HELCOM Recommendation 28E/10, paragraph 5).

Despite the fact that governments are urged to periodically submit reports on the implementation of the No-Special-Fee system, few recent authoritative assessments of the system's effectiveness have been published. According to a joint report from HELCOM member countries on the implementation of the Helsinki Convention of 2005, only three (Denmark, Finland and Germany) out of seven audited countries

\footnotetext{
${ }^{12}$ HELCOM Recommendation 19/8 on waste reception in ports was later superseded by new recommendations where additional types of wastes and garbage were included in the No-SpecialFee system. The latest, valid recommendation on these issues is now (August 2012) "HELCOM Recommendation 28E/10: Application of the No-Special-Fee System to Ship-Generated Wastes and Marine Litter Caught in Fishing Nets in the Baltic Sea Area" which was adopted in November $15,2007$.
} 
had fully implemented the No-Special-Fee system. ${ }^{13}$ According to more recent sources, there are indications that the full implementation of this system still seems to be problematic (Jensen 2011). One suggested reason for this is that some ports, because of the competition among them to attract business, have chosen to charge those using reception facilities more than others. Another factor based on observations is that ports have charged extra fees when pumping sludge outside of regular office hours (Jensen 2011). It is quite clear that the No-Special-Fee system works better in ports where more effective reception facilities have been installed and governments and responsible authorities have both the will and capacity to improve compliance.

\subsection{Discussion}

Contemporary marine governance is often depicted as comprising multilevel and multi-actor interactions, competing knowledge claims and evolving patterns of comanagement, where stakeholders and users play increasingly important roles in overall governance. However, while this is true with regard to fisheries, eutrophication and protection of biodiversity, Baltic Sea shipping is characterised by hierarchical governing structures where IMO acts as a global regulatory hub, EU as a stakeholder and enforcer, HELCOM as an important interface between individual governments and intergovernmental organisations at regional and global scales and governments as key stakeholders typically promoting issue-specific national interests. Despite its globalised nature, modern shipping is to a considerable extent governed by intergovernmental organisations practising a policy mix comprising command and control measures as well as mechanisms to reduce gaps between operators' economic incentive structures and politically agreed upon regulations.

It has been illustrated in four brief examples that both the EU and HELCOM have played important roles in Baltic Sea marine governance. However, their roles have been markedly different from each other. An interesting role that the EU has played at times is that of an enforcer of global conventions at the EU level. The EU has used its legal regulatory instruments and directives, for example, to enforce a faster phasing out of single-hull vessels within the Union and thereby also speed up the global IMO phasing-out process. Another example was when the EU turned the recommended $25 \%$ port inspection frequency by IMO into a mandatory requirement in all EU ports. The EU has, in other words, been able to strengthen global conventions internally and sometimes even influence global governance.

In contrast, HELCOM has no other governance mechanisms at its disposal besides for the Helsinki Convention and the Recommendations which both are built upon consensual decision-making and do not allow for legal enforcement. Despite this, the example of the No-Special-Fee system shows that it can be possible to take

\footnotetext{
${ }^{13}$ Estonia, Latvia, Lithuania and Poland had partially implemented the No-Special-Fee system, whereas Sweden and Russia were not audited.
} 
regulations at higher levels (IMO and EU requirements on port reception facilities) one step further. This could in turn serve as a testing ground and inspiration for similar initiatives at higher levels (e.g. EU). In fact, as has been discussed, a No-Special-Fee system can be implemented throughout the EU building on the example provided by HELCOM. Another aspect of regional governance is that an organisation such as HELCOM can sometimes facilitate subregional collaboration. We illustrated above that joint aerial surveillance for oil pollution was carried out under HELCOM's CEPCO initiative. Although it was also shown that the number of flight hours varies considerably and that not all countries are equally interested in regional cooperation on this matter, it is clear that subregional cooperation among a limited number of reasonably like-minded countries could be valuable and possible for a smaller group. It is typically not the case that participation of all on equal terms is necessary. Sometimes it could be more efficient to let a group of proactive countries take the lead, possibly putting some pressure on others to follow suit.

It is often said that political decision-making and regulatory structures always should be placed at the "appropriate level", that is, at the level that corresponds to the scale of the problem at hand. This is true, but easier said than done. The real challenge is to identify the appropriate level not so much for the sector as such (i.e. shipping) but more importantly for the detailed aspect that needs to be regulated. Moreover, finding the appropriate scale also means that varying opportunities are opened up for different regulatory mechanisms that define how effective and efficient they could be. Although the phasing out of single-hull tankers needs global conventions, unilateral action by dominant powers such as the USA and EU could speed up things when global regulation drags on for too long.

In contrast to command and control mechanisms involved in the phasing out of single-hull tankers, changing incentives have been instrumental to the selective Port State Control and the No-Special-Fee system. The key here has been to look closer at the incentives facing the main actors and trying to change these incentives to induce behaviour that results in safer shipping. It should be noted that in all these cases, there is a global convention at the bottom formalising what has been possible to reach consensus on. Regulations at lower levels or using other means always have to be undertaken within the boundaries set by these higher level agreements in order to avoid inconsistencies. But there are often different ways to improve the enforcement of these regulations and adapt them to regional conditions without threatening the consistency of the global convention, as shown by especially the Port State Control and the No-Special-Fee system examples.

Finally, addressing incentives and capability in marine governance is not only important in relation to operators but also in relation to governments as well. It is no coincidence that Sweden has so many more flight hours than Russia. Sweden and Finland especially have been proactive in implementing regional environmental regulation in the Baltic Sea. Likewise, it is not surprising that the Baltic States have had more problems than the Scandinavian countries in the implementation of the No-Special-Fee system. It is quite natural that proactive countries such as Sweden and Finland tend to exaggerate the amount of common interest in addressing threats to the Baltic Sea environment. The simple reason for this is that it might be in their 
strategic interest to do so in order to induce less interested countries to do more. However, officially recognising differences in national interests and capability might be important in order to set the stage for negotiations under more realistic preconditions. This could mean that proactive countries will need to contribute more than others to monitoring, surveillance, training in Port State Control procedures and part financing of port reception facilities in countries less rich in resources and other initiatives. This might be preferable to negotiation breakdown or severe implementation gaps. Here, HELCOM as well as EU arenas could prove instrumental in facilitating the finding of workable agreements among the Baltic Sea governments.

Acknowledgements This chapter is based on research undertaken within the research programme "Environmental Risk Governance of the Baltic Sea" (2009-2015, Michael Gilek programme coordinator). The research involved research teams from Södertörn University in Sweden, Åbo Akademi University in Finland, Dialogik/Stuttgart University in Germany and Gdansk University in Poland. The funding came from the Foundation for Baltic and East European Studies and the European Community's Seventh Framework Programme (2007-2013) under grant agreement no. 217246 made with the joint Baltic Sea research and development programme BONUS, as well as from the German Federal Ministry of Education and Research (BMBF), the Swedish Environmental Protection Agency, the Swedish Research Council FORMAS, the Polish Ministry of Science and Higher Education and the Academy of Finland. I wish to express my warm appreciation to these institutions for enabling me to conduct this research, to all participants in the research programme that directly or indirectly provided useful input, to all informants for sharing their experiences and to the two reviewers for their constructive comments on an earlier version of the chapter.

Open Access This chapter is distributed under the terms of the Creative Commons AttributionNoncommercial 2.5 License (http://creativecommons.org/licenses/by-nc/2.5/) which permits any noncommercial use, distribution, and reproduction in any medium, provided the original author(s) and source are credited.

The images or other third party material in this chapter are included in the work's Creative Commons license, unless indicated otherwise in the credit line; if such material is not included in the work's Creative Commons license and the respective action is not permitted by statutory regulation, users will need to obtain permission from the license holder to duplicate, adapt or reproduce the material.

\section{References}

Aksu S, Vassalos D, Tuzcu C, Mikelis N, Swift P (2004) A risk based design methodology for pollution prevention and control. RINA International Conference on Design and Operation of Double Hull Tankers, London

Bach I, Flinders M (eds) (2004) Multi-level governance. Oxford University Press, Oxford

Bennet P (2000) Environmental governance and private actors: enrolling insurers in international maritime regulation. Polit Geogr 19(7):875-899

DeSombre ER (2006) Flagging standards: globalization and environmental, safety, and labor regulations at sea. MIT Press, Cambridge

French-McCay DP (2009) Oil spill impact modeling - development and validation. Environ Toxicol Chem 23(10):2441-2456

Hardin G (1968) The tragedy of the commons. Science 162(3859):1243-1248

Hassler B (2003a) Science and politics of foreign aid - Swedish environmental support to the Baltic States. Kluwer Academic Publishers, Dordrecht

Hassler B (2003b) Protecting the Baltic Sea - the Helsinki convention and national interests. In: Stokke OS (ed) Yearbook of international co-operation on environment and development. Earthscan, London 
Hassler B (2008) Individual incentives, collective action, and institutional cooperation - Sweden and the case of Baltic Sea oil transports. J Environ Policy Plan 10(4):339-358

Hassler B (2010) Global regimes, regional adaptation; environmental safety in Baltic Sea oil transportation. Marit Policy Manag 37(5):489-504

Hassler B (2011) Accidental versus operational oil spills from shipping in the Baltic Sea - risk governance and management strategies. AMBIO 40:170-178

HELCOM (2012) Annual 2012 HELCOM report on illegal discharges observed during aerial surveillance, 2013, Helsinki

HELCOM (2014) Annual 2013 HELCOM report on illegal discharges observed during aerial surveillance, 2013, Helsinki

Höfer T (2003) Tanker safety and coastal environment: Prestige, Erika and what else? Environ Sci Pollut Res 10(1):1-5

IMO (1999) Comprehensive manual on port reception facilities, 2nd edn. Ashford Press, London

IMO (2011a) Member states, IGOs and NGOs. Available from: http://www.imo.org/About/ Membership/Pages/Default.aspx. Accessed 27 Jun 2012

IMO (2011b) Construction requirements for oil tankers. Available from: http://www.imo.org/ OurWork/Environment/PollutionPrevention/OilPollution/Pages/constructionrequirements. aspx\#1. Accessed $31 \mathrm{Jul} 2012$

IMO (2012) Tanker safety - preventing accidental pollution. Available from: http://www.imo.org/ blast/mainframe.asp?topic_id=155\#double. Accessed 29 Jun 2012

Jensen C (2011) Recommendations for improved and harmonized waste management on board and in ports. The Regional Council in Kalmar County, Kalmar, June 2011

Joas M, Detlef J, Kern K (eds) (2008) Governing a common sea: environmental policies in the Baltic Sea region. Earthscan, London

Keohane RO (2002) Power and governance in a partially globalized world. Routledge, London

Knapp S, Frances PH (2008) Econometric analysis to differentiate effects of various ship safety inspections. Mar Policy 32(4):653-662

Knudsen OF, Hassler B (2011) IMO legislation and its implementation: accident risk, vessel deficiencies and national administrative practices. Mar Policy 35(2):201-207

Mason M (2003) Civil liability for oil pollution damage: examining the evolving scope for environmental compensation in the international regime. Mar Policy 27(1):1-12

MEPC (2007) Revised consolidated format for reporting alleged inadequacies of port reception facilities. MEPC.1/Circ.469/Rev.1, 13 Jul 2007

Mikelis N (2010) IMO's action plan on tackling the inadequacy of port reception facilities. Powerpoint presentation presented at the workshop "Ships' waste - time for action" in Brussels, 14 October 2010 and organised by EUROSHORE and FEBEM-FEGE

Mitchell RB (1994) Intentional oil pollution at sea: environmental policy and treaty compliance. MIT Press, Cambridge, MA

Mitchell RD, McConnell ML, Roginko A, Barrett A (1999) International vessel-source oil pollution. In: Young $\mathrm{O}$ (ed) The effectiveness of international environmental regimes - causal connections and behavioral mechanisms. MIT Press, Cambridge, MA

National Research Council (2003) Oil in the sea III - inputs, fates and effects. The National Academic Press, Washington, DC

Oberthür S, Gehring T (eds) (2006) Institutional interaction in global environmental governance synergy and conflict among international and EU policies. MIT Press, Cambridge, MA

Paris MoU (2012a) Ship risk profile. Available from: http://www.parismou.org/Inspection_efforts/ Inspections/Ship_risk_profile/\#503dec47-c60f-466c-9887-a2354722cf19. Accessed 2 Mar 2012

Paris MoU (2012b) A port state control preview. Available from: http://www.parismou.org/ Organization/30_years_of_Paris_MoU_on_Port_State_Control/2012.07.02/A_Port_State_ Control_preview.htm. Accessed 31 Jul 2012

Paris MoU (2012c) New inspection regime: port state control reporting obligations. Available from: https://www.parismou.org/Content/PublishedMedia/613aa272-374d-4ead-9ba1-6acf5dc5a25c/ Reporting\%20obligation.pdf. Accessed 31 Jul 2012

Summaries of EU Legislation (29-08-2011) Maritime safety: accelerated phacing-in of doublehall tankers. Available from: http://europa.eu/legislation_summaries/transport/waterborne_ transport/124231_en.htm. Accessed 07 May 2015 